\title{
Product platform replacement: impact of performance objectives, innovation speed, and competition
}

To appear in the International Journal of Technology Management

\author{
Maud Van den Broeke ${ }^{(a)} *$ Bart Devoldere ${ }^{(b)}$ \\ Stefan Creemers ${ }^{(a, c)} \bullet$ Robert Boute ${ }^{(b, c)}$
}

(a) Operations Department, IESEG School of Management, Lille, France

(b) Technology and Operations Management Area, Vlerick Business School, Gent, Belgium

(c) Research Center for Operations Management, KU Leuven, Leuven, Belgium

Product platforms are assets shared by multiple products. Their primary purpose is to offer product variety while keeping time-to-market and operational costs down. As new products are developed over time, the question arises when to replace a platform. The repetitive use of the same platform for multiple product generations keeps platform development time and costs low. As the platform gets obsolete, however, the time and efforts to adapt the platform to the newest product will go up. With these dynamics in mind, we develop a simulation model to gain insight into the desired platform replacement planning. We examine how platform replacements are impacted by a firm's performance objectives, the speed of innovation, and the competitive landscape.

Keywords: product platforms, platform replacement, simulation, performance objectives, innovation

\section{Introduction}

The increase in product variety in response to customer needs and fierce competition puts pressure on operations, such as costs related to inventory, production, and research and development, as well as time-to-market of new product introductions (Sawhney, 1998). To manage the increased product variety in a cost- and time-efficient manner, companies in diverse industries have introduced product

\footnotetext{
${ }^{*}$ Corresponding author. E-mail addresses of all authors: m.vandenbroeke@ieseg.fr (+32 (0)497 079167$)$ bart.devoldere@vlerick.com, s.creemers@ieseg.fr, robert.boute@vlerick.com
} 


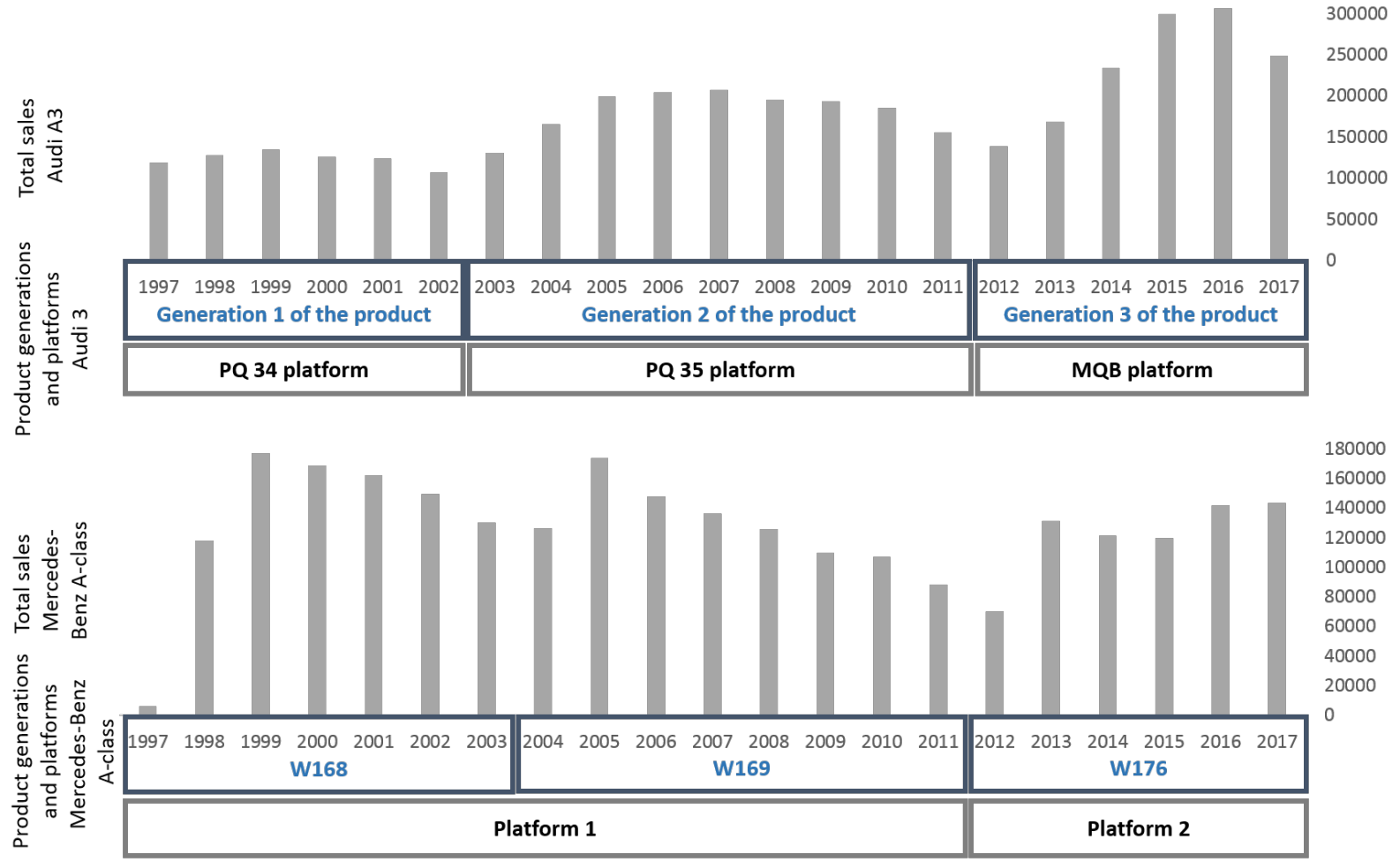

Figure 1: Total sales figures, product generation, and platform replacement planning, 1997-2017, for Audi A3 and Mercedes-Benz A-class cars (Source: Carsalesbase-website (2018)).

platforms (Simpson et al. 2014; Muffatto and Roveda, 2002). Product platforms can be defined as "a set of subsystems and interfaces that form a common structure from which a set of products can be derived" (Meyer and Lehnerd, 1997). The use of platforms is well-known in automotive, where the chassis of the car is used as a common platform for multiple products (Alizon et al., 2009). Also other companies, including HP, Xerox, Canon, Sony, Boeing, and Swatch, make use of common platforms to cope with their product variety (de Weck et al., 2003).

In this article we focus on one aspect that has received surprisingly little research attention in the product platform literature - platform replacement planning (Zhang, 2015). The timely replacement of a platform is important for companies to keep up with current technologies and to respond to competition in dynamic environments. The car manufacturer Volvo, for instance, recently replaced its platform to accommodate for electric cars (Lambert, 2017). Barco, a Belgian technology company that specializes in digital projection and imaging technology, is another example that replaced its first generation platforms of its high-tech medical displays (Boute et al., 2017). 
The timing of platform replacement may have an important impact on the company's performance (McGrath, 1996; Meyer et al., 2018). Kodak, a technology company producing camera-related products, for instance, was able to win back market share from it competitor Fuji by introducing a new platform (Robertson and Ulrich, 1998). Their platform allowed them to introduce more new products in a shorter time than Fuji. Figure 1 illustrates the sales figures of two competing products, the Audi A3 and Mercedes-Benz A-class (Carsalesbase-website, 2018), in the period 19972017. For each new product generation of the Audi A3, a new platform was developed, resp. PQ34 and PQ35 for the first and second generation, and the MQB platform for the third generation. For the Mercedes-Benz A-class, the first two product generations (W168 and W169) were derived from the same platform, and a new platform was developed for the third product generation (W176). Both companies seem to have a different planning with regard to their platform replacements. The sales numbers also illustrate the life cycle of product demand. These contemporary examples show the relevance and need to study platform replacement planning.

Replacing platforms frequently requires high development costs and time. On the other hand, an obsolete platform may require long adaptation times to adjust the old platform to the newest product needs. We develop a simulation model that takes these trade-offs into account to determine the optimal platform replacement, i.e., for how many product generations should a platform be used. While its logic spurs from existing literature and reality, it is a stylized, generalizable model. First, we analyze how the platform replacement timings are impacted by the company's performance objectives, such as profit or market share maximization, or risk minimization. Second, we also analyze the speed at which new technologies become available. We denote the latter by the speed of innovation. Finally, we also study the effect of the competitor's platform replacement decisions. These factors were posited by Keeney and Raiffa (1993), Magnusson and Pasche (2014), and Kang et al. (2012), respectively.

Our results provide guidance for firms on their platform replacement timings, and show how contextual factors, such as innovation speed and competition, can be taken into account. For instance, we find that it is not always optimal to replace platforms faster than the competition. Our results also help firms understand why different departments, each with their own performance objectives, might have conflicting opinions on the optimal platform replacement timings. For instance, when one wants to minimize risk, the platform typically lasts longer compared to when 
one aims to maximize profit and market share.

\section{$2 \quad$ Literature Review}

The literature on product platforms is rich, as illustrated by the reviews of Jiao et al. (2007), Simpson et al. (2014), and Zhang (2015). Platforms enable mass customization by combining the benefits of mass production, such as reduced development time and cost due to the standardization of the platforms, with the ability to offer a wide range of customized products that can be derived from the platforms (Muffatto, 1999a; Fogliatto et al., 2012). One should also take into account, however, the cost and time to customize the platforms to new products (Van den Broeke et al. 2015), the cost of potential over-design of the platforms (Krishnan and Gupta, 2001a), and the risk of platform obsolescence (Kang et al., 2012, Tyagi et al., 2015).

Extensive studies are devoted to finding the optimal platform design and configuration (e.g., Agard and Bassetto, 2013; Farrell and Simpson, 2010). Although several authors, such as Meyer and Lehnerd (1997), Krishnan and Gupta (2001a), and Halman et al. (2003), highlight the importance of platform replacement, to date, the topic is under-explored (Sköld and Karlsson, 2012, Zhang, 2015). Our study aims to fill that gap.

Driven by continuous changes in technology and their potential obsolescence, product platforms may be altered, modified, or even abandoned over time (Mäkinen et al., 2014). Platforms thus have a life cycle, which is different from the life cycle of the products derived from them Wortmann and Alblas, 2009; Levandowski, 2014). When new products are introduced, one must decide whether they will be developed from an existing platform or whether an entirely new platform is developed for these (and future) new products (Halman et al., 2003). Meyer and Lehnerd (1997) refer to the former as "platform adaptation", indicating that particular subsystems of the platform are enhanced or changed or new subsystems added, without completely overhauling the existing system. The latter, referred to as "platform replacement", indicates that the product architecture is redesigned to incorporate major new platform subsystems and interfaces. Frequent platform replacements comes with high development costs (Halman et al., 2003). An obsolete platform may on the other hand not be capable to cope with new product innovations, if the company fails to replace its platforms timely. 
Pasche and Magnusson (2011) and Tyagi et al. (2015) deal with the problem of platform obsolescence. They study how a robust platform can (or should) be configured to cope with new product generations, through component and architectural innovation. Jana et al. (2018) investigate the value of postponing the start of the platform development. This allows to capture more technological innovation in its platform. To keep time-to-market short, the product development time can be shorted at the expense of an increased development cost. Kang et al. (2012) offset the cost efficiencies in development when extending the platform lifetime against the lost sales due to obsolete platform technologies.

Our simulation model contributes to the literature by examining the impact of different performance objectives, such as profit and market share maximization or minimization of financial risk, whereas Kang et al. (2012), for instance, only focus on profit maximization. Our underlying motivation is that product development decisions, including platform replacement, almost always entail multiple objectives, among which there are trade-offs or priorities (Keeney and Raiffa, 1993). Moreover, these objectives often serve as key performance metrics to assess R\&D project success and new product development (McNally et al., 2013).

Our contribution also lies in the impact analysis of contextual factors, such as the industry's innovation speed and competition. Mäkinen et al. (2014) expressed this need. For example, Kang et al. (2012) found an unanticipated relationship between competition and the platform lifetime. On the one hand, they expect that under severe competition, companies competitively introduce new products and product innovation is accelerated. This may drive more frequent platform replacements to include the latest technologies. On the other hand, however, they empirically found that the platform lifetime is not necessarily shorter, or can even be longer, under severe competition. As competitors take away market share, revenues may be lower, which is in turn compensated by a reduction of their development costs. There seems to be a need to better understand how contextual factors, such as competition, influence platform replacement planning.

In the next section, we describe our simulation model and its assumptions. Section 4 is devoted to a discussion of the results of our analysis. 


\begin{tabular}{c|ccccccc}
$q_{\max }$ & \multicolumn{7}{|c}{ Product introduction } \\
& $j=1$ & $j=2$ & $j=3$ & $j=4$ & $j=5$ & $j=6$ & $j=\ldots$ \\
\hline 0 & $\mathrm{x}$ & $\mathrm{x}$ & $\mathrm{x}$ & $\mathrm{x}$ & $\mathrm{x}$ & $\mathrm{x}$ & $\mathrm{x}$ \\
1 & $\mathrm{x}$ & $\mathrm{o}$ & $\mathrm{x}$ & $\mathrm{o}$ & $\mathrm{x}$ & $\mathrm{O}$ & $\mathrm{x}$ \\
2 & $\mathrm{x}$ & $\mathrm{O}$ & $\mathrm{O}$ & $\mathrm{x}$ & $\mathrm{o}$ & $\mathrm{o}$ & $\mathrm{x}$ \\
3 & $\mathrm{x}$ & $\mathrm{o}$ & $\mathrm{O}$ & $\mathrm{o}$ & $\mathrm{x}$ & $\mathrm{o}$ & $\mathrm{o}$ \\
4 & $\mathrm{x}$ & $\mathrm{o}$ & $\mathrm{O}$ & $\mathrm{o}$ & $\mathrm{o}$ & $\mathrm{x}$ & $\mathrm{o}$
\end{tabular}

Table 1: Platforms are renewed every $q_{\max }+1$ product introductions ( $\mathrm{x}=$ new platform development; $\mathrm{o}=$ existing platform adaptation for the $j$-th product introduction).

\section{Problem description and simulation model}

We simulate a duopoly setting with two competing firms, wherein each company introduces $n$ new products over time. A new product introduction $j \in\{1,2, \ldots, n\}$ is linked to the availability of new technologies. Similar to Huisman (2013) and Sahal (1974), we characterize the speed at which new technologies become available by a Poisson process with rate parameter $\lambda$; we designate this parameter "speed of innovation". When a new technological innovation emerges, one can decide to either develop (replace) a new platform with this newest technology, or one can re-use the existing platform, and derive the new technology from this existing platform Khadke and Gershenson, 2008; Muffatto, 1999b).

We assume in our model that the focal firm has one main competitor, who also introduces the same product generations $j \in\{1, \ldots, n\}$, inspired by the same speed of innovation. Both companies make their platform replacement planning when their first platform is developed and this planning remains unchanged over time. We consider both the situation where the focal firm and its competitor make their platform replacement planning independently from each other, as well as when they take into account each other's possible platform replacement planning. We also assume that a company does not have more than one platform in use at the same time. Platforms are replaced every $q_{\max }+1$ product introductions, where $q_{\max }$ is the decision variable. A new developed platform for the $j$-th product introduction is denoted platform $i=j$. When the $j$-th product is adapted from an existing platform, platform $i=j-q$, where $0<q \leq q_{\max }$. When $q_{\max }=0$, a new platform is developed for each new product and the platform is never reused for a subsequent product. When $q_{\max }=1$, a platform is used for two consecutive product introductions, etc. The higher $q_{\max }$, the less platform replacements. Without loss of generalizability, we assume 
5 products to be the maximum number of products derived from a platform before it becomes technically infeasible to derive a new product from that platform (i.e., $q_{\max }$ is at most 4 ). Table 1 illustrates this principle.

We now discuss the trade-offs inherent to the platform replacement decision (section 3.1), the characterization of product demand (section 3.2), the role of competition (section 3.3), followed by a definition of our three performance objectives (section 3.4). Finally, we discuss the design of the simulation experiment (section 3.5).

\subsection{Trade-off between platform development and platform adaptation time}

A company's platform replacement decision is to a large extent driven by the trade-off between the time to develop a new platform and the time to adapt an existing platform to the newest product. We refer to Van den Broeke and Boute (2014) for an illustration of platform development versus adaptation times for the development of high-tech screens. In our model, we assume that both platform development and adaptation times are stochastic, and denote $t_{i}^{d}$ the random variable of the time required to develop platform $i$, and $t_{j, q}^{a}$ the time required to adapt product $j$ from platform $i=j-q\left(\right.$ with $\left.t_{j, 0}^{a}=0\right)$.

In line with Krishnan and Gupta (2001a), we assume that developing a platform from scratch takes more time than adapting an existing platform to the product's needs, unless the platform is getting close to obsolescence, at which point adaptation time can exceed platform development time (Mäkinen et al., 2014). We model the time to adapt product $j$ from its previous platform $i=j-1$ as a percentage $0 \leq \alpha_{a} \leq 1$ of the time to develop a new platform $i=j$. As the gap $q$ between platform $i$ and product $j$ increases, the adaptation time increases accordingly. More specifically, the time required to adapt product $j$ from platform $i=j-q$, given a platform development time $t_{i}^{d}$, is given by:

$$
t_{j, q}^{a}=\sum_{i=j-q+1}^{j} \alpha_{a} t_{i}^{d} .
$$

For example, if $\alpha_{a}=0.50$, then the adaptation time to derive product $j$ from platform $i=j-1$ is half the time of developing a new platform $i=j$, or $t_{j, 1}^{a}=0.50 t_{j}^{d}$. Analogously, the adaptation time to derive product $j$ from a platform that was developed at $i=j-2$, is then $t_{j, 2}^{a}=0.50 t_{j-1}^{d}+0.50 t_{j}^{d}$. Table 2 provides an illustrative example for a sample of development times when $\alpha_{a}=0.50$. The 


\begin{tabular}{c|ccccc}
$j$ & $t_{j}^{d}$ & $t_{j, 1}^{a}$ & $t_{j, 2}^{a}$ & $t_{j, 3}^{a}$ & $\cdots$ \\
\hline 1 & 9 & & & & $\cdots$ \\
2 & 12 & 6 & & & $\cdots$ \\
3 & 8 & 4 & 10 & & $\cdots$ \\
4 & 10 & 5 & 9 & 15 & $\ldots$
\end{tabular}

Table 2: Illustrative example of platform development and adaptation times for $\alpha_{a}=0.50$.

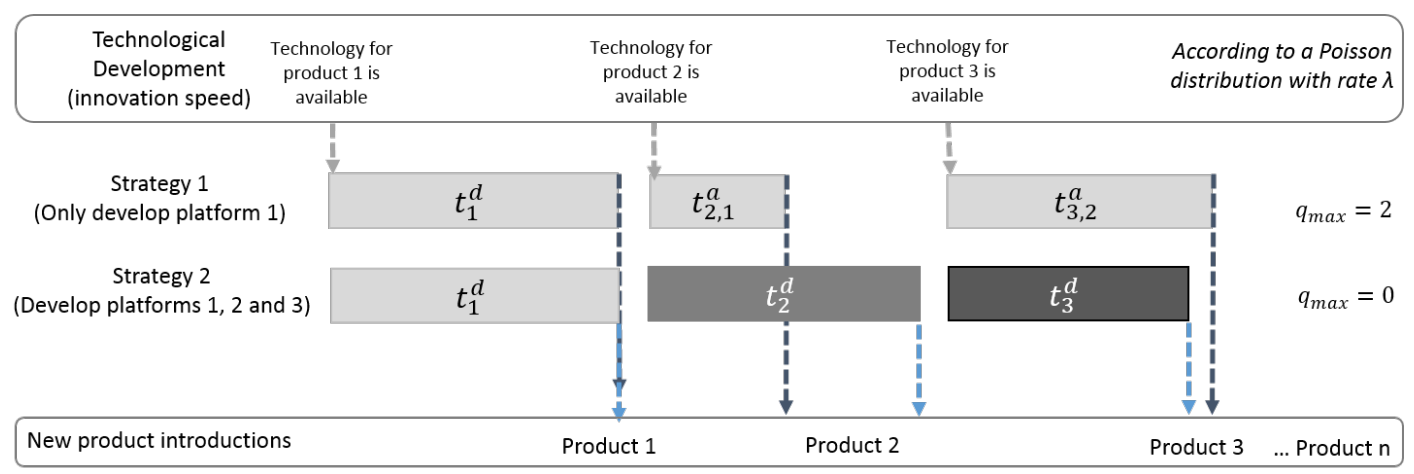

Figure 2: Illustration of two different platform replacement strategies for three consecutive product introductions.

time-to-market of product $j$ is then given by $t_{j}^{d}$ if a new platform is developed, or $t_{j, q}^{a}$ if it is adapted from a previous platform $j-q$. It illustrates how the total time required for a product introduction is influenced by the decision whether it is developed from a new platform or adapted from an existing platform.

Figure 2 illustrates two different platform replacement strategies, and their impact on the resulting time-to-market for product introductions $j \in\{1,2,3\}$. In platform replacement strategy 1 , platform 1 is used for three consecutive product generations $\left(q_{\max }=2\right)$; in strategy 2 , a new platform is developed for each new product generation $\left(q_{\max }=0\right)$. Whereas strategy 1 benefits from more platform commonality and less platform development time and costs, strategy 2 benefits from less platform obsolescence and no platform adaptation times. Figure 2 shows how these different platform replacement strategies impact the time of entering the market with the different products. Take for instance the introduction of product 2: when it takes longer to develop a new platform 2 instead of adjusting platform 1 to meet the requirements of product 2 (i.e., if $t_{2,1}^{a}<t_{2}^{d}$ ), product 2 will be launched sooner using strategy 1 compared to strategy 2. However, as platform 1 gets more obsolete, it may well be that developing a new platform is less time-consuming than adjusting the existing platform 1. For product 3, for instance, platform replacement strategy 1 could involve a 


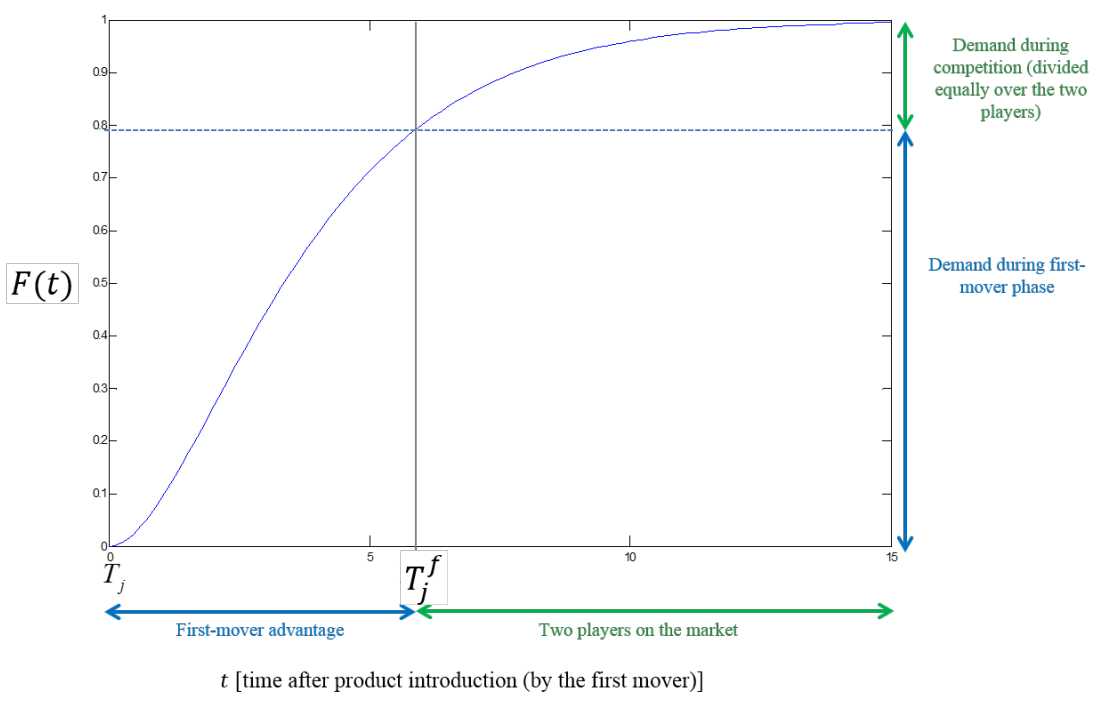

Figure 3: Cumulative demand distribution for product $j$ after its introduction to the market $T_{j}$ and the market introduction by its competitor at time $T_{j}^{f}$.

longer product introduction time than strategy 2 when $t_{3,2}^{a}>t_{3}^{d}$.

\subsection{Demand distribution}

We characterize the demand for each product $j$ over time $t$ after its product introduction by a chisquared distribution, resembling its S-shaped product life cycle (see Day (1981)). The assumption of chi-squared distributed demand is also supported by the sales statistics in Figure 1; moreover it has the advantage of being easily adapted using different parameter settings.

Without loss of insights, we assume the degree of freedom $(k)$ of the chi-squared distribution equal to 4. Product demand after its introduction is given by the cumulative density function $F$. We relate the chi-square distributed demand to the speed of innovation, characterized by $\lambda$. If $\lambda=1$, we assume half of a product's demand is realized before the subsequent product is introduced. When $\lambda<1$, the speed of innovation is slower, and more than half of demand is realized before the subsequent product is introduced. The opposite holds for $\lambda>1$.

The market demand for product $j$ is impacted by the introduction of the subsequent product $j+1$, and the cannibalization effect from this product. When product $j+1$ is launched, we assume a portion $\alpha_{c}$ of the demand for product $j$ is cannibalized or lost, with $0 \leq \alpha_{c} \leq 1$ (Mason and Milne, 1994). A higher value of $\alpha_{c}$ means more cannibalization; a value of $\alpha_{c}=1$ represents the extreme 
case where demand drops to zero after the introduction of a product successor. We assume that product $j$ only cannibalizes the demand of product $j-1$, and not the former product generations. Figure 3 illustrates the demand distribution in the period after its introduction.

\subsection{Competition}

We assume the focal firm has one competitor, who faces the same product introductions (inspired by the same technologies) and also decides on its platform replacements. A firm can replace platforms slower, faster, or at the same speed as its competitor. At each new product introduction, the focal firm competes with its competitor to capture market share.

The company that is the first to introduce the $j$-th product generation, has a time-to-market of

$T_{j}$. The time-to-market of the market follower is denoted by $T_{j}^{f} \geq T_{j}$. The firm's time-to-market depends on its platform replacement planning, as discussed previously. We assume that, as soon as the market follower introduces its product at time $T_{j}^{f}$, market demand is shared equally between both companies.

We consider both the situation where the focal firm and its competitor make their platform replacement decisions independently from each other, as well as when they take into account each other's possible platform replacement decision. In the latter situation, we derive a Nash equilibrium of the focal firm's and competitor's platform replacement planning decisions.

\subsection{Performance objectives}

Our study considers three distinct performance objectives (i.e., market share, profit and risk) which are prevalent in the new product introduction and platform development literature. Platform replacement planning impacts the speed at which new products can be introduced into the market. This speed-to-market is a critical factor for sustaining competitive advantage and market share (Datar et al., 1997; Kerin et al., 1992), as well as for profitability (McNally et al., 2011). Profit and its constitutes sales, driven by market share, and (development) costs, are well-known measures in the platform-based product development literature (Krishnan and Gupta, 2001b). This explains why we study market share and profit as performance objectives. Since there is often a trade-off between profit and risk (Van Mieghem, 2011), and since risk plays an important role in new product development (McNally et al., 2013), we also study risk as a performance objective. 


\begin{tabular}{cccc}
\hline $\begin{array}{c}\text { Focal } \\
\text { firm is } \\
\text { first mover }\end{array}$ & $\begin{array}{c}\text { Cannibal- } \\
\text { ization } \\
\text { of subsequent } \\
\text { products }\end{array}$ & $\begin{array}{c}\text { The subsequent product } j+1 \\
\text { is introduced before the } \\
\text { market follower introduces } \\
\text { its product } j\end{array}$ & Revenue $V_{j}=$ \\
\hline Yes & No & No & $F\left(T_{j}^{f}\right)+\frac{1}{2}\left(1.0-F\left(T_{j}^{f}\right)\right)$ \\
Yes & Yes & Yes & $F\left(T_{j+1}\right)+\left(F\left(T_{j}^{f}\right)-F\left(T_{j+1}\right)\right)\left(1-\alpha_{c}\right)+\left(1.0-F\left(T_{j}^{f}\right)\right) \frac{1}{2}\left(1-\alpha_{c}\right)$ \\
Yes & Yes & No & $F\left(T_{j}^{f}\right)+\left(F\left(T_{j+1}\right)-F\left(T_{j}^{f}\right)\right) \frac{1}{2}+\left(1.0-F\left(T_{j+1}\right)\right) \frac{1}{2}\left(1-\alpha_{c}\right)$ \\
No & No & No & $\left(1.0-F\left(T_{j}^{f}\right)\right) \frac{1}{2}$ \\
No & Yes & Yes & $\left(1.0-F\left(T_{j}^{f}\right)\right) \frac{1}{2}\left(1-\alpha_{c}\right)$ \\
No & Yes & No & $\left(F\left(T_{j+1}\right)-F\left(T_{j}^{f}\right)\right) \frac{1}{2}+\left(1.0-F\left(T_{j+1}\right)\right) \frac{1}{2}\left(1-\alpha_{c}\right)$ \\
\hline
\end{tabular}

Table 3: Calculation of market share under changing environments.

The first objective we consider is the maximization of the market share, defined as the proportion of total demand captured by the focal firm. Assuming the price at which products are sold to be fixed over time and equal to 1 , revenue is driven purely by market share. We denote market share for product $j$ obtained by the focal firm by $V_{j}$. As $F(\infty)=1$, the maximum attainable revenue for product $j$ is then $V_{j}^{\max }=1$. The total expected market share over all $n$ products is denoted by $V=\sum_{j=1}^{n} V_{j}$, and the average market share per product is reported by:

$$
\text { Average market share }=\frac{V}{n}=\frac{\sum_{j=1}^{n} V_{j}}{n} \text {. }
$$

Table 3 shows different situations that impact the market share $V_{j}$. For instance, suppose the focal company is the first mover (i.e., it launches product $j$ at time $T_{j}$, earlier than its competitor's launch time at $T_{j}^{f}$ ), and there is no cannibalization from subsequent product introductions. Then, the focal firm can respond to all market demand until his competitor enters the market at time $T_{j}^{f}$, at which point the remaining market demand is divided equally between both companies. The market share then equals $F\left(T_{j}^{f}\right)+\frac{1}{2}\left(1.0-F\left(T_{j}^{f}\right)\right)$. This setting is also illustrated in Figure 3

The second performance metric that we consider is profit, which depends on the market share $V$ just explained and platform development costs. Each time a new platform is developed, a development cost is incurred, which we express by $\alpha_{d}$, where $0 \leq \alpha_{d} \leq 1$. For instance, the platform development costs at Barco, the provider of high-tech medical screens, represents the lion's hare of their product cost, equaling around $35 \%$ of revenues $\left(\alpha_{d}=0.35\right)$ (Boute et al. 2017$)$. The total profit over all $n$ products can then be expressed as $\Pi=V-\frac{n}{q_{\max }+1} \alpha_{d}$, where $\frac{n}{q_{\max }+1}$ is the number of platforms developed (see Table 1), and the average profit per product equals: 


\begin{tabular}{ccc}
\hline Parameter & Values & Interpretation when parameter value increases \\
\hline$\alpha_{a}$ & $\{0,0.50,1\}$ & Longer platform adaptation time \\
$\alpha_{d}$ & $\{0,0.2,0.4,0.8\}$ & Higher platform development cost \\
$\alpha_{c}$ & $\{0,0.50,1\}$ & More cannibalization \\
$\lambda$ & $\{0.5,1,4,20\}$ & Higher speed of innovation \\
\hline
\end{tabular}

Table 4: Parameter settings used in the computational experiment.

$$
\text { Average profit }=\frac{\Pi}{n}=\frac{V-\frac{n \alpha_{d}}{q_{\max }+1}}{n}
$$

Finally, we consider risk, measured by variance of profits $\Pi$ (Van Mieghem, 2011), as the third performance metric. In our model, the focal firm's profit under a given setting and for a given platform replacement decision, also depends on the competitor's platform replacement planning. As the competitor's platform replacement timings are unknown to the focal firm, the focal firm's profit is subject to uncertainty. Some stakeholders may want to minimize this profit uncertainty.

$$
\text { Average risk }=\operatorname{Var}\left(\frac{\Pi}{n}\right)
$$

\subsection{Design of the simulation experiment}

We set up a computational experiment to analyze the optimal platform replacement planning strategy under different environments. The parameter values established for our experimental design are summarized in Table 4 and cover a wide range of industry environments. The interpretation of these parameters was explained in the previous section (we provide a glossary of all notations used in Appendix). Platform development times $t_{i}^{d}$ are assumed to be uniformly distributed between 50 and 150 periods. In total, 144 settings are observed over $n=60$ product introductions. The simulation model was coded in Visual Studio $C^{++}$. We used common random numbers and 450,000 simulation iterations in order to guarantee accuracy of our results. For each simulation run, we captured market share, profit, and risk of both the firm and its competitor in each of the 144 settings, and given the platform replacement planning decision of each party. 

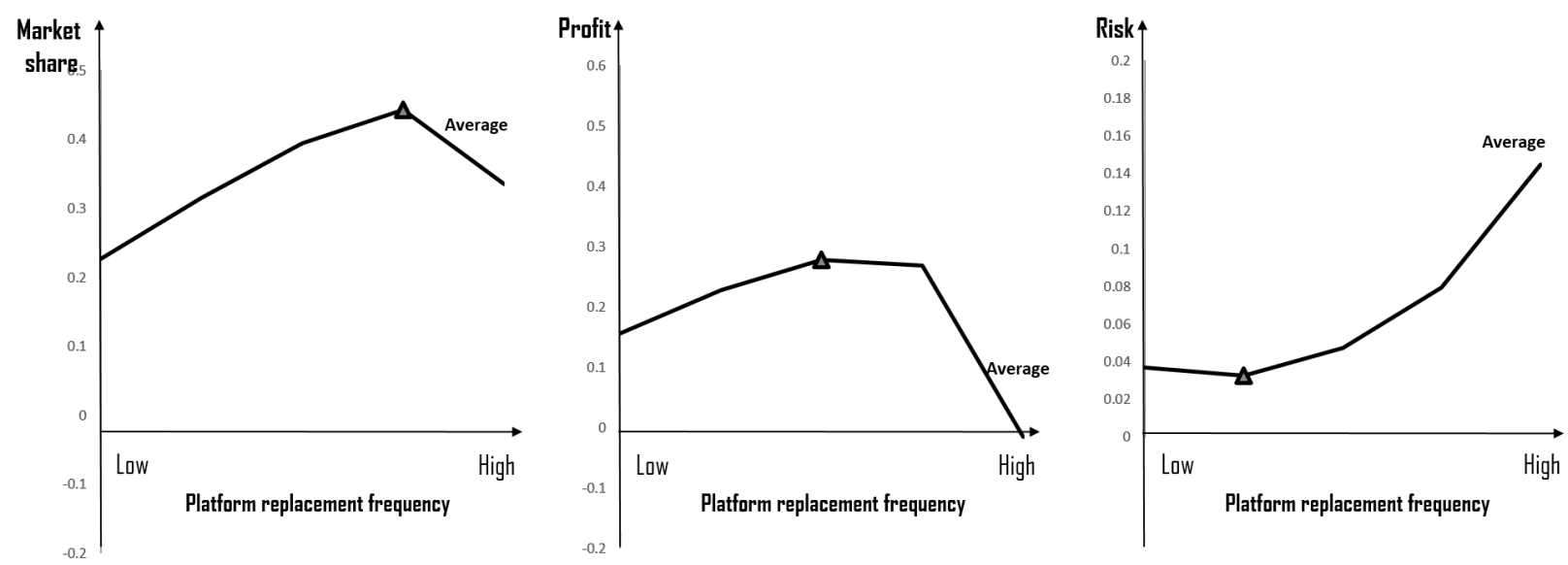

Figure 4: Market share, profit, and risk under different platform replacement frequencies averaged over all computational results $(\boldsymbol{\Lambda}=$ optimal replacement frequency).

\section{Results and insights}

We will first discuss the general impact of platform replacement planning on the firm's performance. Next, we discuss the impact of the different environment parameters: platform adaptation time $\alpha_{a}$, platform development cost $\alpha_{d}$, innovation speed $\lambda$, and cannibalization $\alpha_{c}$. Last, we will discuss the impact of competition.

\subsection{Impact of performance objectives}

We evaluate firm performance in three aspects: market share, profit, and risk. Figure 4 reflects the firm's performance averaged over all simulations in the 144 settings in our simulation experiment. We report performance in function of the platform replacement frequency, equal to $4-q_{\max }$. When $q_{\max }=0$, a new platform is developed for each new product and the platform replacement frequency is high. When $q_{\max }=4$, a platform is used for 4 consecutive product generations, and the platform replacement frequency is low.

We observe a concave relationship between the platform replacement frequency and the market share and profit, whereas it is convex related with risk. In other words, extreme platform replacement strategies (i.e., always or never replacing) are often suboptimal, and the right balance must be sought. This makes practical sense, as it is too costly and time-consuming to develop a new platform for each new product, just as it becomes too costly and time-consuming to adapt an obsolete platform to match the needs of new product innovations. When risk minimization is key, 

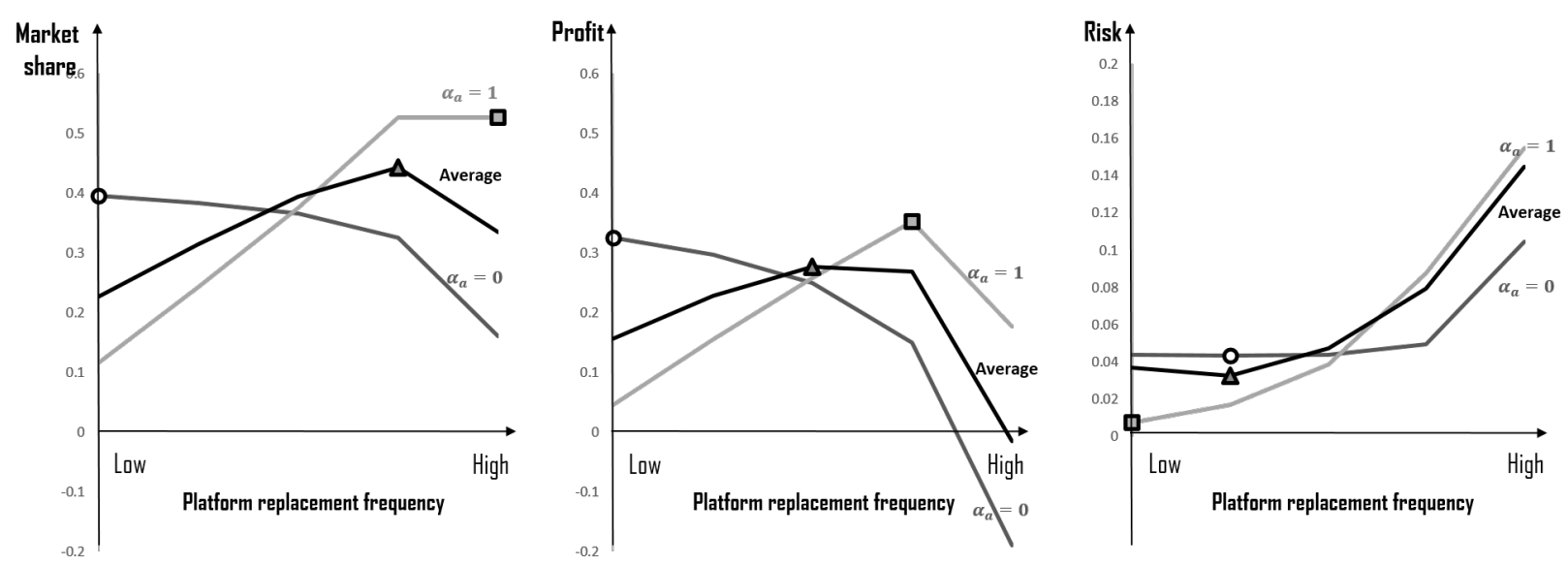

Figure 5: Impact of platform adaptation time on optimal platform replacement frequency under different firm objectives ( $o=$ optimal replacement frequency under short platform adaptation time $\left(\alpha_{a}=0\right)$ and $\square=$ optimal replacement frequency under long platform adaptation time $\left(\alpha_{a}=1\right)$ ).

one wants to avoid extreme platform replacement strategies (i.e., replacing platforms very slow or fast), as the profits for these strategies can vary a lot under different settings and under different platform replacement decisions of the competitor.

We observe that the optimal platform replacement frequency is higher under market share maximization when compared to profit maximization. This can be explained by the fact that a myopic focus on market share ignores the costs of developing a new platform, and hence platforms will be replaced faster. Under risk minimization, we observe that platforms are replaced less frequently. As different departments in a firm often have different performance objectives (e.g., operations, sales, and finance might strive to minimize costs, maximize market share, or minimize risk, respectively), it explains why certain companies struggle to make platform replacement decisions. Moreover, it means that companies with a similar product portfolio might still adapt a different platform replacement strategy, depending on their performance objective.

\subsection{Impact of platform adaptation time and development cost}

Figure 5illustrates how the platform replacement strategies differ in function of platform adaptation time $\alpha_{a}$. If adaptation times increase, the disadvantage of long platform development times (and the subsequent risk of introducing a product later than the competitor) becomes less pronounced. Therefore, we see that as platform adaptation times increase, platforms are replaced faster under 

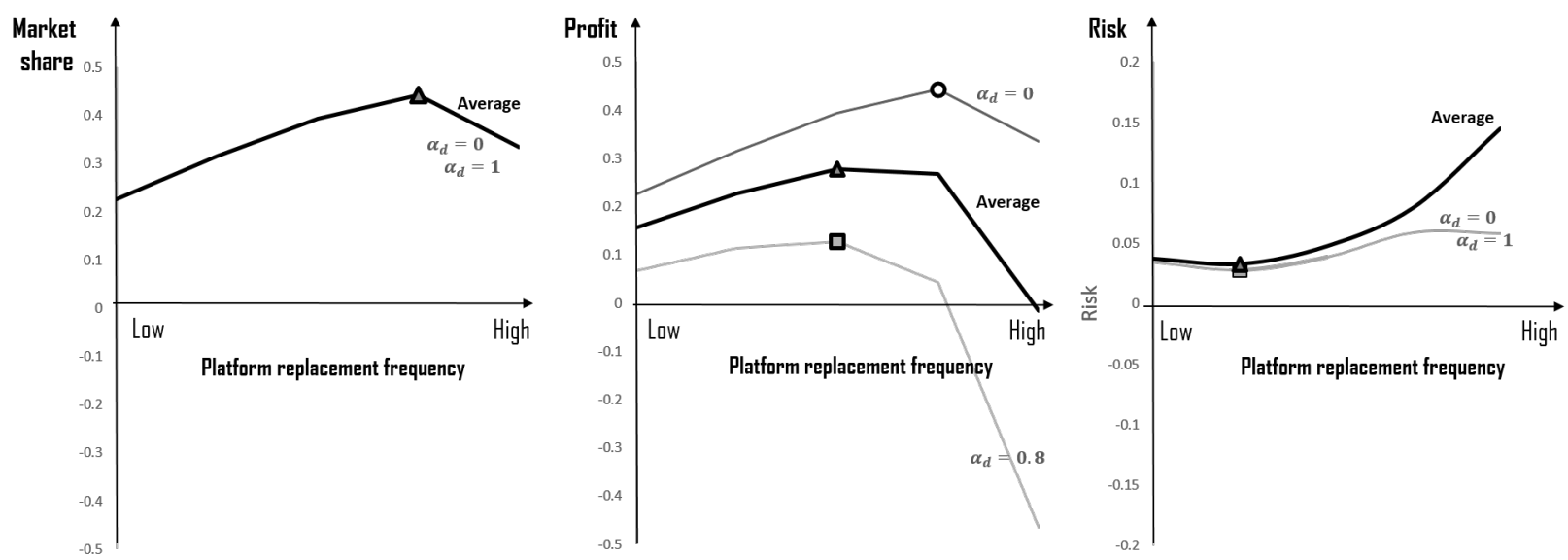

Figure 6: Impact of platform development cost on optimal platform replacement frequency under different firm objectives ( $o=$ optimal replacement frequency under low platform development cost $\left(\alpha_{d}=0\right)$ and $\square=$ optimal platform development cost under high platform development cost $\left.\left(\alpha_{d}=0.8\right)\right)$.

market share or profit maximization. The opposite is true under risk minimization. The explanation of this effect comes down to the impact of a change in the platform adaptation time on uncertainty in profits. The risk, or uncertainty in profits, stems from the fact that the focal firm does not know his competitor's time to market. The latter is linked to his platform replacement strategy. When platform adaptations times are short compared to the platform development times, it is relatively certain that the time-to-market is later than competition when platforms are frequently replaced (due to the relatively long development times). With longer platform adaptation times, however, the expectation of being later to the market becomes less certain. This makes less frequent platform replacements more appealing to reduce risk.

The impact of platform development cost $\alpha_{d}$ is as expected: we find that platforms are more frequently replaced under lower platform development costs when profit is maximized (see Fig. 6). This is in line with the findings of Kang et al. (2012) who show that lower platform development costs shorten a platform's lifetime. As development costs increase, firms want to leverage the larger development costs over more product generations. Whereas previous research has mostly focused on the impact of platform development costs, our results show the importance of taking platform adaptation time into account as well, when making platform replacement decisions. 

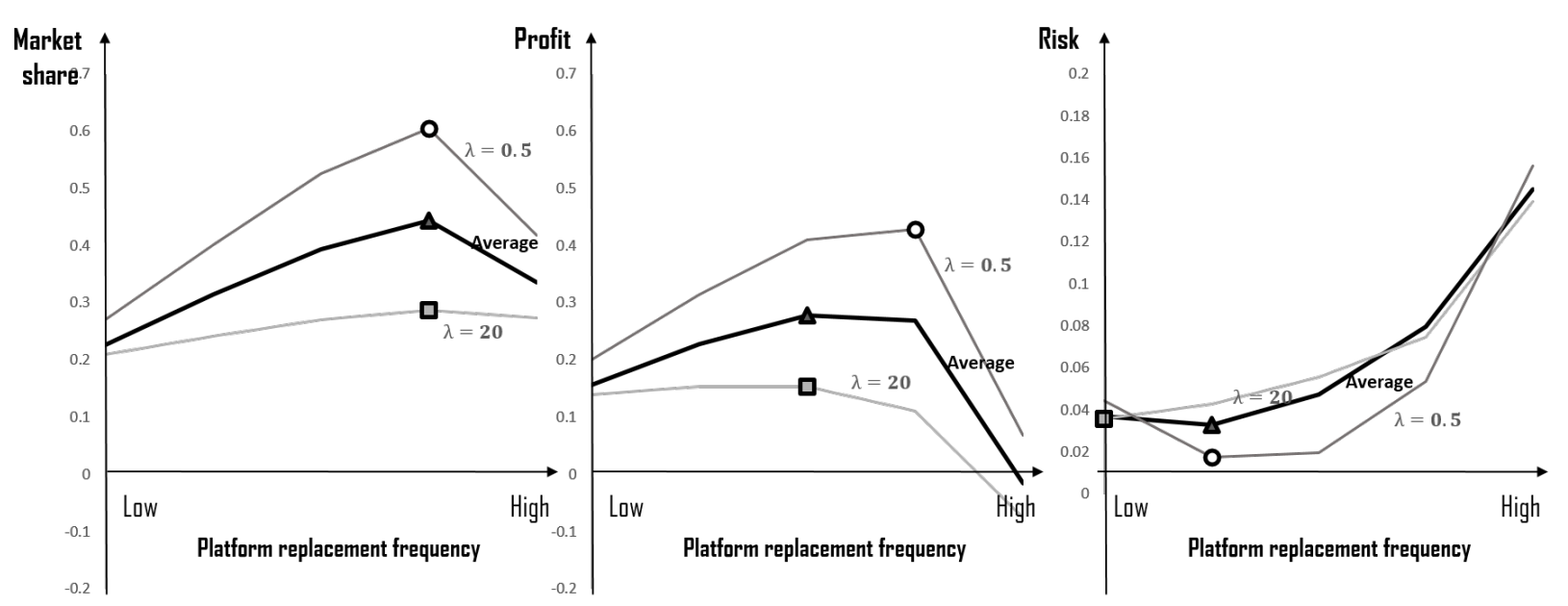

Figure 7: The impact of speed of innovation on platform replacement frequency under different firm objectives ( $o=$ optimal replacement frequency under low innovation speed $(\lambda=0.5)$ and $\square=$ optimal replacement frequency under high innovation speed $(\lambda=20))$.

\subsection{Impact of innovation speed and cannibalization}

In this section, we discuss the impact of innovation speed and the level of cannibalization of new product introductions. Results are shown in Figure 7 where a smaller value of $\lambda$ indicates slower innovation speed, i.e., the speed of technological innovation in the industry is slower. We observe that innovation speed does not necessarily have a marked impact on optimal replacement planning, but when it does, a higher innovation speed would lead to slower platform replacement, and vice versa. This is in line with Thomas (2014) and Chai et al. (2012) who found that technological turbulence increases the platform lifetime to reduce development cost and adapt faster to changes. We do observe, however, that differences in performance between the different replacement strategies become less pronounced as innovations are introduced more rapidly. This can be explained as follows. If innovations speed is low, there is less cannibalization as the time between new product introductions is longer, and the full potential of the demand can be realized. If innovation speed is high, on the other hand, cannibalization leads to a higher loss of market share. Our results show that the impact of cannibalization is almost identical to that of innovation speed: higher levels of cannibalization result in lower profits/market share (for the same innovation speed).

In Figure 8 we visualize the firm's average profit and risk (i.e., profit variance) from different platform replacement strategies, under different settings. We refer to this as the mean variance or 

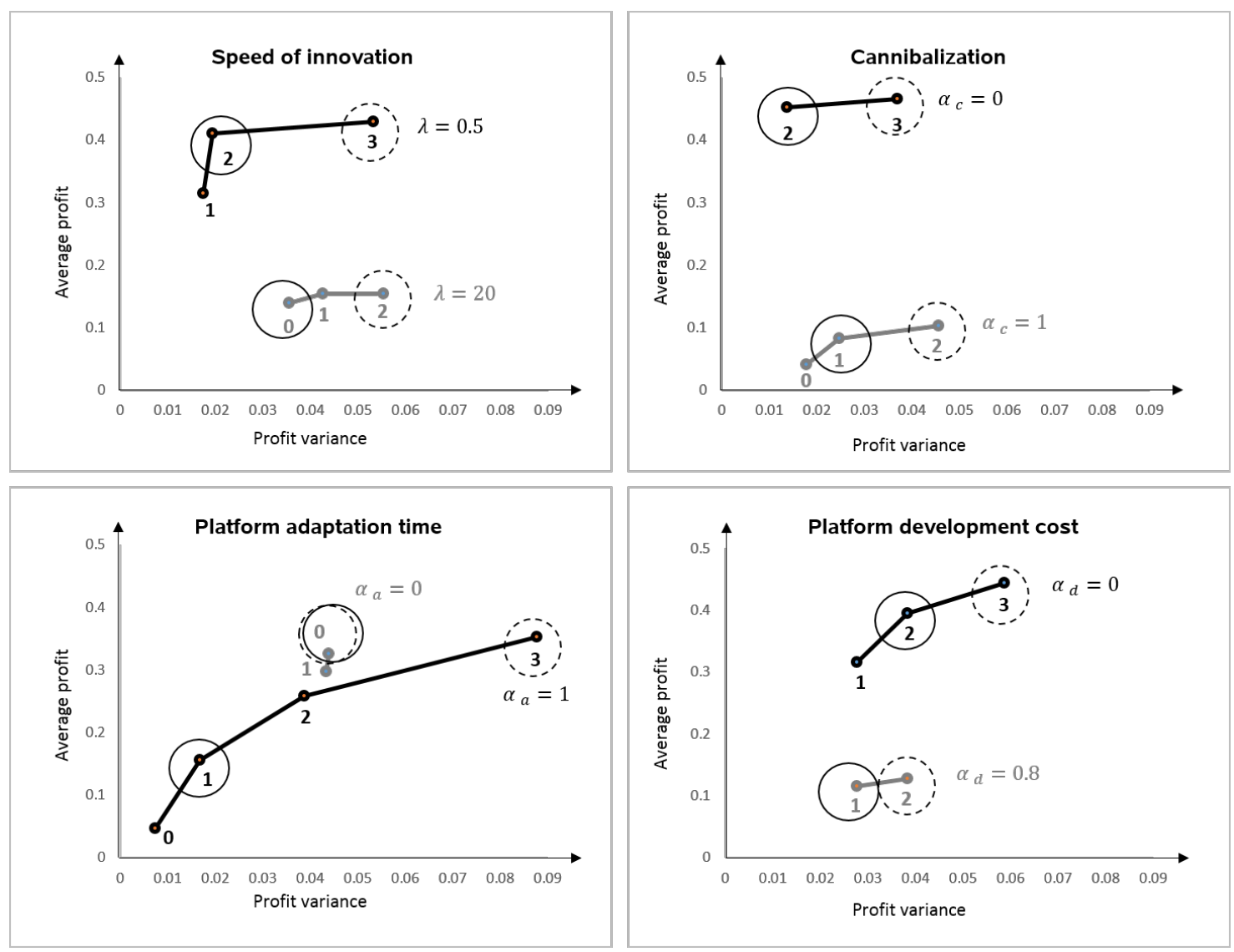

Figure 8: Platform replacement frequency decisions on the mean variance frontier depend on the speed of innovation $\lambda$, the level of cannibalization $\alpha_{c}$, the platform development time $\alpha_{d}$ and the platform adaptation time $\alpha_{a}$. A solid circle represents the platform replacement strategy with the highest return-to-risk ratio, a dotted circle represents the platform replacement strategy with the highest profit.

efficiency frontier (see Van Mieghem (2007) and references therein). Note that platform replacement strategies that are not part of the efficiency frontier are not visualized. When the company is riskneutral, it will choose the platform replacement strategy with the highest profit (each time circled with a dotted line in Figure 8). However, when the company is risk-averse, it trades off profit against the risk. In Figure 8, platform replacement strategies with the highest return-to-risk ratio (i.e., average profit over profit variance) are each time circled with a solid line. This shows the optimal platform replacement decision for a firm who wants to take both profit and risk into account. We find that a slower platform replacement generally goes hand-in-hand with lower risk (except for $\alpha_{a}=0$ ), and that the extreme of frequent platform replacements (i.e., a replacement frequency of 4) is never part of the efficiency frontier for the settings considered. 


\begin{tabular}{|c|c|c|c|c|c|c|}
\cline { 3 - 7 } \multicolumn{1}{c|}{} & \multicolumn{5}{c|}{ Competitor's platform replacement frequency } \\
\cline { 2 - 7 } \multicolumn{1}{c|}{ Profit of the focal firm } & 4 (high) & 3 & 2 & 1 & 0 (low) \\
\hline \multirow{2}{*}{$\begin{array}{c}\text { Platform } \\
\text { replacement } \\
\text { frequency } \\
\text { of the }\end{array}$} & 4 (high) & 0.097 & -0.139 & -0.112 & 0.092 & 0.334 \\
\cline { 2 - 7 } focal firm & 3 & 0.352 & $\mathbf{0 . 1 5 2}$ & $\mathbf{0 . 2 4 4}$ & 0.349 & 0.384 \\
\cline { 2 - 7 } & 2 & $\mathbf{0 . 3 8 8}$ & 0.106 & 0.199 & $\mathbf{0 . 3 8 3}$ & 0.440 \\
\cline { 2 - 7 } & 1 & 0.245 & 0.014 & 0.042 & 0.238 & $\mathbf{0 . 4 7 1}$ \\
\hline
\end{tabular}

\begin{tabular}{|c|c|c|c|c|c|c|}
\cline { 3 - 7 } \multicolumn{2}{c|}{} & \multicolumn{5}{|c|}{ Competitor's platform replacement frequency } \\
\cline { 2 - 7 } \multicolumn{2}{c|}{ Profit of the competitor } & 4 (high) & 3 & 2 & 1 & 0 (low) \\
\hline \multirow{2}{*}{$\begin{array}{c}\text { Platform } \\
\text { replacement }\end{array}$} & 4 (high) & 0.098 & 0.352 & $\mathbf{0 . 3 8 8}$ & 0.245 & 0.029 \\
\cline { 2 - 7 } frequency & 3 & -0.139 & $\mathbf{0 . 1 5 3}$ & 0.106 & 0.014 & -0.014 \\
\cline { 2 - 7 } of the & 2 & -0.112 & $\mathbf{0 . 2 4 4}$ & 0.200 & 0.042 & -0.007 \\
\cline { 2 - 7 } focal firm & 1 & 0.093 & 0.349 & $\mathbf{0 . 3 8 3}$ & 0.239 & 0.026 \\
\cline { 2 - 7 } & 0 (low) & 0.334 & 0.384 & 0.440 & $\mathbf{0 . 4 7 1}$ & 0.276 \\
\hline
\end{tabular}

Table 5: Profits of the focal firm and its competitor in the setting $\alpha_{a}=0.5, \lambda=1, \alpha_{d}=0.2, \alpha_{c}=1$.

Note that from the simulation results, we also observe that the profit loss of sub-optimal profitmaximizing platform replacement planning increases as platform adaptation time, innovation speed, and cannibalization increase.

\subsection{Impact of competition}

Our simulation reports the focal firm's performance for each platform replacement strategy of the competitor, and for each of the 144 settings (as illustrated for one such setting in Table 5). In the results discussed above, we each time averaged the focal firm's performances under the competitor's different strategies for platform replacement. We will now study in more detail the impact of the competitor's platform replacement decisions.

We consider two situations. In the first situation, we analyze the focal firm's performance under the assumption that the focal firm and its competitor decide their platform replacement strategy independently from each other. In the second situation, we analyze the focal firm's performance when the focal firm and its competitor change their platform replacement strategy as a response to each other's platform replacement strategy. In the latter situation, we look for the Nash equilibrium. We illustrate the difference between these two situations with the example in Table 5. First, if the focal firm and competitor independently from each other determine their platform replacement 
strategy, the focal firm would be well advised to choose platform replacement frequency 3,2 or 1 , if the competitor chooses platform replacement frequency 3 or 2, 4 or 1 , and 0 , respectively (see the bold figures in Table 5. Second, based on the simulation output, we can also use the Nash equilibrium. The reasoning is that if the focal firm opts for replacement frequency 2 or 3 , the competitor will opt for frequency 3 , and the focal firm will in turn opt for frequency 3 . If the focal firm opts for frequency 1 , the competitor will opt for frequency 2 . In turn the focal firm will change its decision to frequency 3. Consequently, the steady state is that the focal and its competitor opt for platform replacement frequency 3 .

We now discuss the general findings (over all 144 scenarios). For the situation where the firm and competitor make platform replacement decisions independently from each other, Figure 9 summarizes the optimal strategies of the focal firm depending on (1) the competitor's platform replacement strategy, and (2) the performance objective being considered. Under market share and profit maximization, we find that the focal firm should adopt a slightly higher or lower replacement frequency in response to competitor's extremely low or high replacement frequency, respectively. With respect to risk, we find that there is an overall tendency toward replacing more slowly or at equal frequency as the competitor. These insights contribute to those of Kang et al. (2012), who modeled the impact of competitive intensity (measured as the probability of the competitor introducing a product) on platform replacement. They found that, contrary to expectation, higher competition caused a lower replacement frequency, to reduce development costs.

For the situation where the firm and competitor take into account each other's platform replacement strategy, we find that both companies tend to choose the same platform replacement frequency, aiming at simultaneous product introduction (see also the example in Table 5 , where both the focal and competitive firm select a replacement frequency of 3). However, this equilibrium often (i.e., in 100 of the 144 settings analyzed) does not lead to the maximum achievable profit for both firms. For instance, the Nash equilibrium in Table 5 leads to a total profit of $0.305(0.152$ $+0.153), 44.7 \%$ lower than the maximum total profit of 0.552 when both parties would choose a platform replacement frequency of zero. The average loss in profit in the Nash equilibrium over all 144 scenarios is around $28.5 \%$.

We learn that competition has an important impact on the firm's platform replacement decisions and their performance. This means that platform replacement decisions should not only be driven 

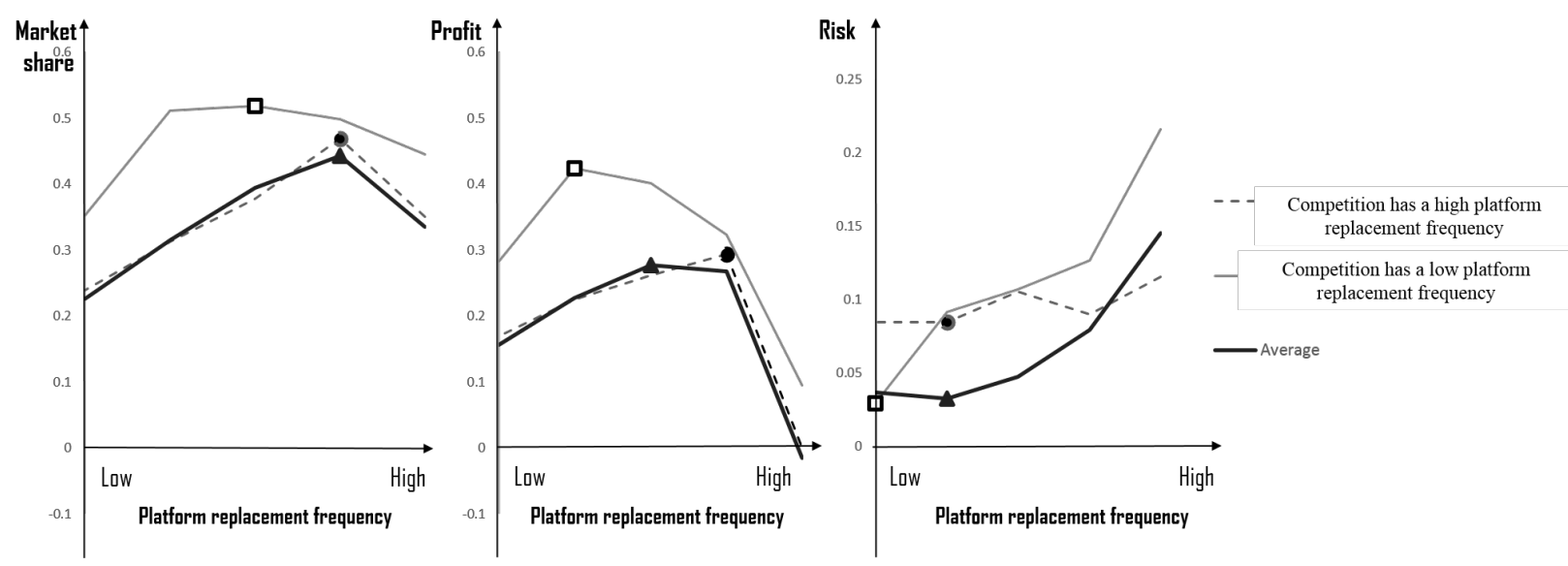

Figure 9: Impact of competitor's platform planning on platform replacement decisions under different performance objectives $(\bullet=$ optimal replacement frequency under high platform replacement frequency of the competitor, and $\square=$ optimal replacement frequency under low platform replacement frequency of the competitor).

by a firm's internal development process and technological innovation, but should also take into account the competitive environment.

\section{Conclusion}

In this article we address the question when a platform should be replaced to cope with future product generations. Replacing a platform requires substantial development time and costs, but failing to do so may result in platform obsolescence, leading to longer platform adaptation times to customize the platform to the latest product. Platform replacement planning impacts not only development costs, but also time-to-market, which in turn impacts the firm's agility to capture market demand. The latter also depends on the competitor's platform replacement decisions. We develop a simulation model that takes all these dynamics into account.

Our analysis shows that higher innovation speed does not necessarily lead to more frequent platform replacement, and that replacing platforms faster than one's competitor is not always favorable. Optimal platform replacement timing is strongly dependent on performance objectives: shareholders may want to minimize financial risk, sales are driven by market share maximization, whereas good management strives to maximize profit. Given the impact of platform replacement on many levels, different departments may have conflicting opinions, leading to philosophical discussions 
and more challenges into reaching platform replacement decisions. Using our model, such internal philosophical discussions can rely on factual analysis objectively assessed.

The results in our paper are based on a simulation model. Future research could focus on extending our model and relaxing certain assumptions. For instance, a limitation of our model is that we assume market demand is divided equally when two firms are active in the market, but other settings may also be relevant for future research, e.g., what happens when a larger portion of the demand remains with the first mover. Moreover, it would be interesting to check the validity of our insights when a firm has multiple platforms simultaneously. While our model assumes there is only one platform in use at a time, future research could allow for a dynamic platform replacement frequency, meaning that the frequency could change over time. This could lead to new insights under the game-theoretical analysis where we consider the response of the competitor. Another extension could consider the impact of having more than two firms competing for demand.

\section{References}

Agard, Bruno, Samuel Bassetto. 2013. Modular design of product families for quality and cost. International Journal of Production Research 51(6) 1648-1667.

Alizon, Fabrice, Steven B Shooter, Timothy W Simpson. 2009. Henry Ford and the model T: lessons for product platforming and mass customization. Design Studies 30(5) 588-605.

Boute, Robert N, Maud M Van den Broeke, Kristof A Deneire. 2017. Barco implements platformbased product development in its healthcare division. Interfaces 48(1) 35-44.

Carsalesbase-website. 2018. http://carsalesbase.com/. [Online; accessed 12-07-2018].

Chai, Kah-Hin, Qi Wang, Michael Song, Johannes IM Halman, Aarnout C Brombacher. 2012. Understanding competencies in platform-based product development: Antecedents and outcomes. Journal of Product Innovation Management 29(3) 452-472.

Datar, Srikant, Clark Jordan, Sunder Kekre, Surendra Rajiv, Kannan Srinivasan. 1997. New product development structures and time-to-market. Management Science 43(4) 452-464. 
Day, George S. 1981. The product life cycle: analysis and applications issues. Journal of Marketing 45(4) 60-67.

de Weck, Olivier L, Eun Suk Suh, David Chang. 2003. Product family and platform portfolio optimization. ASME 2003 International Design Engineering Technical Conferences and Computers and Information in Engineering Conference. American Society of Mechanical Engineers, $175-185$.

Farrell, Ronald S, Timothy W Simpson. 2010. Improving cost effectiveness in an existing product line using component product platforms. International Journal of Production Research 48(11) 3299-3317.

Fogliatto, Flavio S, Giovani JC Da Silveira, Denis Borenstein. 2012. The mass customization decade: An updated review of the literature. International Journal of Production Economics 138(1) 14-25.

Halman, Johannes IM, Adrian P Hofer, Wim Van Vuuren. 2003. Platform-driven development of product families: linking theory with practice. Journal of Product Innovation Management 20(2) $149-162$.

Huisman, Kuno JM. 2013. Technology investment: A game theoretic real options approach, vol. 28. Springer Science \& Business Media.

Jana, Paul, Stephen C Graves, Martin Grunow. 2018. Balancing benefits and flexibility losses in platform planning. Available at SSRN 3134037 .

Jiao, Jianxin Roger, Timothy W Simpson, Zahed Siddique. 2007. Product family design and platform-based product development: a state-of-the-art review. Journal of Intelligent Manufacturing 18(1) 5-29.

Kang, Chang Muk, Yoo S Hong, Woonghee Tim Huh. 2012. Platform replacement planning for management of product family obsolescence. IIE Transactions 44(12) 1115-1131.

Keeney, Ralph L, Howard Raiffa. 1993. Decisions with multiple objectives: preferences and value trade-offs. Cambridge university press. 
Kerin, Roger A, P Rajan Varadarajan, Robert A Peterson. 1992. First-mover advantage: A synthesis, conceptual framework, and research propositions. The Journal of Marketing 33-52.

Khadke, Kiran, John K Gershenson. 2008. Technology-driven product platform development. International Journal of Product Development 6(3-4) 353-374.

Krishnan, Vish, Saurabh Gupta. 2001a. Appropriateness and impact of platform-based product development. Management Science 47(1) 52-68.

Krishnan, Vish, Saurabh Gupta. 2001b. Appropriateness and impact of platform-based product development. Management Science 47(1) 52-68.

Lambert, Frederic. 2017. Volvo says its first all-electric vehicle is coming in 2019 with battery packs up to 100 kwh. https://electrek.co/2017/02/09/volvo-first-all-electric-vehicle-2019/ Feb 9.

Levandowski, Christoffer. 2014. Platform lifecycle support using set-based concurrent engineering. Chalmers University of Technology.

Magnusson, Mats, Maximilian Pasche. 2014. A contingency-based approach to the use of product platforms and modules in new product development. Journal of Product Innovation Management 31(3) 434-450.

Mäkinen, Saku J, Marko Seppänen, J Roland Ortt. 2014. Introduction to the special issue: Platforms, contingencies and new product development. Journal of Product Innovation Management 31(3) 412-416.

Mason, Charlotte H, George R Milne. 1994. An approach for identifying cannibalization within product line extensions and multi-brand strategies. Journal of Business Research 31(2) 163-170.

McGrath, Michael E. 1996. Setting the PACE in product development: A guide to product and cycle-time excellence. Routledge.

McNally, Regina C, M Billur Akdeniz, Roger J Calantone. 2011. New product development processes and new product profitability: Exploring the mediating role of speed to market and product quality. Journal of Product Innovation Management 28(s1) 63-77. 
McNally, Regina C, Serdar S Durmuşoğlu, Roger J Calantone. 2013. New product portfolio management decisions: antecedents and consequences. Journal of Product Innovation Management 30(2) 245-261.

Meyer, M. H., A. P. Lehnerd. 1997. The power of product platforms: building value and cost leadership. The Free Press, New York.

Meyer, Marc H, Oleksiy Osiyevskyy, Dirk Libaers, Marcel van Hugten. 2018. Does product platforming pay off? Journal of Product Innovation Management 35(1) 66-87.

Muffatto, Moreno. 1999a. Introducing a platform strategy in product development. International Journal of Production Economics 60 145-153.

Muffatto, Moreno. 1999b. Platform strategies in international new product development. International Journal of Operations \& Production Management 19(5/6) 449-460.

Muffatto, Moreno, Marco Roveda. 2002. Product architecture and platforms: a conceptual framework. International Journal of Technology Management 24(1) 1-16.

Pasche, Maximilian, Mats Magnusson. 2011. Continuous innovation and improvement of product platforms. International Journal of Technology Management 56(2/3/4) 256-271.

Robertson, David, Karl Ulrich. 1998. Planning for product platforms. Sloan management review 39(4) 19.

Sahal, Devendra. 1974. Generalized poisson and related models of technological innovation. Technological Forecasting and Social Change 6 403-436.

Sawhney, Mohanbir S. 1998. Leveraged high-variety strategies: from portfolio thinking to platform thinking. Journal of the Academy of Marketing Science 26(1) 54-61.

Simpson, Timothy W, J Jiao, Zahed Siddique, Katja Hölttä-Otto. 2014. Advances in product family and product platform design. New York: Springer .

Sköld, Martin, Christer Karlsson. 2012. Product platform replacements: challenges to managers. International Journal of Operations \& Production Management 32(6) 746-766. 
Thomas, Ellen. 2014. Platform-based product design and environmental turbulence: The mediating role of strategic flexibility. European Journal of Innovation Management 17(1) 107-124.

Tyagi, Satish, et al. 2015. Optimization of a platform configuration with generational changes. International Journal of Production Economics 169 299-309.

Van den Broeke, Maud, Robert Boute. 2014. Advantages and disadvantages of product platforms: insights from literature. Review of Business and Economic Literature 58(3) 186-210.

Van den Broeke, Maud, Robert Boute, Behzad Samii. 2015. Evaluation of product-platform decisions based on total supply chain costs. International Journal of Production Research 53(18) $1-19$.

Van Mieghem, Jan A. 2007. Risk mitigation in newsvendor networks: Resource diversification, flexibility, sharing, and hedging. Management Science 53(8) 1269-1288.

Van Mieghem, Jan A. 2011. Risk management and operational hedging: An overview. Handbook of Integrated Risk Management in Global Supply Chains 1-35.

Wortmann, Hans, Alex Alblas. 2009. Product platform life cycles: a multiple case study. International Journal of Technology Management 48(2) 188-201.

Zhang, Linda L. 2015. A literature review on multitype platforming and framework for future research. International Journal of Production Economics 168 1-12. 


\section{Appendix}

\section{Glossary of notations}

\begin{tabular}{c|l} 
Notation & Interpretation \\
\hline$j$ & Product number \\
$i$ & Platform number \\
$\lambda$ & Total number of products \\
$k$ & Rate of new technology/innovation becoming available under the Poisson distribution \\
$q$ & Setting (degrees of freedom) of the chi-squared distribution \\
$q_{\max }+1$ & The gap between the platform and product, with $q_{\max }$ the maximum gap \\
$4-q_{\max }$ & Platform of products derived from the same platform \\
$n$ & Number of platforms developed in total \\
$q_{\max }+1$ & The development time of platform $i$ \\
$t_{i}^{d}$ & The adaptation time to derive product $j$ from platform $i=j-q$ \\
$t_{j, q}^{a}$ & Percentage of platform development time, used to calculate the adaptation time \\
$\alpha_{a}$ & Time-to-market of the first mover for product $j$ \\
$T_{j}$ & Time-to-market of the market follower for product $j$ \\
$T_{j}^{f}$ & The level of cannibalization, reflected by the percentage of lost sales \\
$\alpha_{c}$ & of the product $j-1$ when product $j$ is introduced \\
$V_{j}$ & Market share of product $j$ (with the maximum $V_{j}$ equal to 1 ) \\
$\alpha_{d}$ & Percentage of market share, used to calculate the development cost \\
$\Pi$ & Total profit over all $n$ products \\
\hline
\end{tabular}

